\title{
Política social en tiempos de crisis
}

\author{
Social Politicies in Times of Crisis \\ Antonio ANTÓN MoRÓN \\ Universidad Autónoma de Madrid \\ antonio.anton@uam.es
}

Recibido: 10/10/2011

Revisado: 28/11/2011

Aceptado: 22/12/2011

Disponible on line: 15/02/2012

\section{Resumen}

La crisis socioeconómica dura ya cuatro años, con el agravamiento de sus consecuencias sociales de paro masivo, incremento de la desigualdad y nuevas brechas sociales. Las necesidades de protección pública se han ampliado frente a riesgos cada vez mayores para la cohesión social. La gestión política dominante, de carácter liberal-conservador, prioriza los intereses de los mercados financieros, causantes de la crisis. Lejos de regularlos e impulsar la reactivación económica y la creación de empleo, adopta medidas de ajuste y austeridad. La consecuencia es el estancamiento económico y la prolongación de la crisis, con el intento de hacer recaer sus costes nuevamente sobre la mayoría de la sociedad. Sus características son la limitación del porcentaje de gasto público social por habitante respecto del PIB per cápita, la disminución de la intensidad protectora y una reestructuración institucional con mayor segmentación y privatización de servicios públicos. Al mismo tiempo, la mayoría de la población demanda empleo decente y garantías de derechos socioeconómicos y laborales. Las reformas sociales, en este periodo, están condicionadas por esa doble dinámica, con las opciones de una salida de la crisis más regresiva o más equilibrada. El objeto de esta investigación son los cambios de la política social en este contexto. Se analizan el impacto social de la crisis, las características de la reestructuración del Estado de bienestar, la escasa legitimidad ciudadana de los recortes sociales y las dificultades y perspectivas para la reforma social.

Palabras clave: Crisis socioeconómica, desigualdad, ciudadanía, Estado de bienestar, reforma social.

\begin{abstract}
:
The socioeconomic crisis has already lasted four years, its social consequences of massive unemployment, an increase in inequality and new social gaps worsening over time. The need for public protection has widened with the growing risks for social cohesion. The prevailing political management, a liberal-conservative one, prioritizes the interests of the financial markets who are responsible for the crisis. Far from regulating them and pushing forward economic reactivation and job creation, it adopts measures for control and austerity. The consequence is economic stagnation and the prolongation of the crisis, with an attempt to push off its costs again onto the majority of society. Its features are the restriction of the percentage in public social spending per inhabitant in respect to the per capita GDP, a decrease in the strength of protection and an institutional restructuring entailing a bigger segmentation and privatization of public service. At the same time, the majority of the population demands decent employment and guarantees of socioeconomic and labour rights. Social reforms in this period are determined by the dual dynamic, with the option for an exit from the crisis either more regressive or more balanced. The subject of this research is the changes in policies within this context. The social impact of the crisis is analyzed together with the restructuring of the Welfare state, the scare legitimacy of social cuts among the people and the difficulties of and outlook for social reform.
\end{abstract}

Keywords: Socioeconomic crisis, Inequality, Citizenship, Welfare state, Social reform.

Referencia normalizada: Antón Morón, A. (2012): «Política social en tiempos de crisis». Cuadernos de Trabajo Social, 25(1): 49-62.

Sumario: Introducción. 1. Impactos sociales de la crisis socioeconómica. 2. Cambios regresivos y segmentación de la política social. 3. Fundamentos de los servicios públicos y perspectivas de la reforma social. 4. Referencias bibliográficas. 


\section{Introducción}

El objeto de esta investigación son los cambios de la política social en el actual contexto de crisis económica y políticas de austeridad. Primero, detalla los impactos sociales de la crisis, con fuertes desigualdades sociales y grandes déficit de protección social, desde un amplio análisis empírico. Segundo, valora el sentido regresivo de los cambios del Estado de bienestar y los procesos de segmentación de los servicios públicos, con una explicación de la escasa legitimidad ciudadana de los recortes sociales. Tercero, introduce algunas reflexiones teóricas sobre los límites de los fundamentos de los servicios públicos y sociales y, junto con diversos interrogantes, interpreta las dificultades y perspectivas para la reforma social. El rigor científico en el análisis y la interpretación crítica de dinámicas complejas se combinan con la actitud ética a favor del progreso social y la igualdad.

\section{Impactos sociales de la crisis socioeconó- mica}

Dos hechos claves se pueden destacar sobre las repercusiones sociales de la crisis socioeconómica: el paro masivo y el incremento de la desigualdad social. Añadiremos el análisis del esfuerzo público en protección social.

Los datos empíricos muestran la cruda realidad del paro y su persistencia. Según la Encuesta de Población Activa (EPA) del $3^{\circ}$ trimestre de 2011, existen casi 5.000.000 desempleados (4.980.000), con una tasa de paro del 21,5 por ciento, más del doble de la UE-27 y la UE-15 (9,5 por ciento). Más de 1.400.000 hogares tienen todos sus miembros activos en paro y unos 900.000 parados (el 18 por ciento del total) son el sostén principal de sus familias; ambos datos expresan el incremento del riesgo de pobreza intensa. La tasa de paro de la población de origen extranjero $(32,7$ por ciento) es trece puntos superior a la media de las personas de nacionalidad española, y la tasa de desempleo juvenil es el 45,8 por ciento. La trayectoria del paro es muy pronunciada y ascendente: el total de parados (EPA, $3^{\circ}$ trimestre) ha pasado de 1.790 .000 en el año 2007 , a 2.600 .000 en 2008, 4.120.000 en 2009, 4.570 .000 en 2010, y el citado 4.980 .000 en 2011. Las variables económicas aventuran un estancamiento de la economía (crecimiento cero en ese trimestre, según el Banco de España) o incluso otra recesión. Las perspectivas del empleo indican su no mejoría a corto y medio plazo, y esos altos niveles de paro pueden persistir varios años.

Por otra parte (Ministerio de Trabajo, noviembre-2011), 1.600.000 parados, de los 4.420.000 registrados, no cobran prestaciones o subsidios de desempleo; más del 30 por ciento no tienen esa protección pública que llega a cubrir hasta 24 meses, plazo insuficiente ante una crisis prolongada con mucho paro de larga duración. La paga de 400 euros, con condiciones y por un semestre, y las rentas de inserción de las comunidades autónomas no constituyen alternativa suficiente para resolver esa situación de vulnerabilidad.

Con datos provisionales del año 2011, la tasa de riesgo de pobreza (tras las transferencias sociales) es el 21,8 por ciento, más de un punto superior a la del año 2010 (20,7 por ciento), y dos puntos aproximadamente por encima de la media de la última década, en que se había mantenido entre el 19 por ciento y el 20 por ciento. En el año 2009 (19,5 por ciento) el diferencial con la UE-27 (16,4 por ciento) y la UE-15 (16,2 por ciento) ya era superior en más de tres puntos.

Existen diversos criterios para evaluar el desarrollo social (Antón, 2009; Inglehart y Welzel, 2005; Sen, 2001). En este sentido, para analizar el segundo hecho significativo, el incremento de la desigualdad socioeconómica, se utilizarán los indicadores de Eurostat ${ }^{1}$. España ha mantenido en la década pasada un nivel de desigualdad superior a la media de la UE-15, y en los dos últimos años, 2009 y 2010, a diferencia de la UE-15, ha sufrido un incremento significativo hasta situarse en 33,9 puntos (Gráfico 1). Atendiendo al coeficiente de GINI, el país con menos desigualdad, europea y mundial es Suecia con 24,1 puntos. Alema-

${ }^{1}$ Eurostat utiliza dos tipos de indicadores: el ratio \$80/\$20 (relación entre los ingresos del 20 por ciento de la población que más ingresa y los ingresos del 20 por ciento que menos ingresa), y el coeficiente (o índice) GINI que mide la desigualdad (100 desigualdad absoluta y 0 igualdad total). 


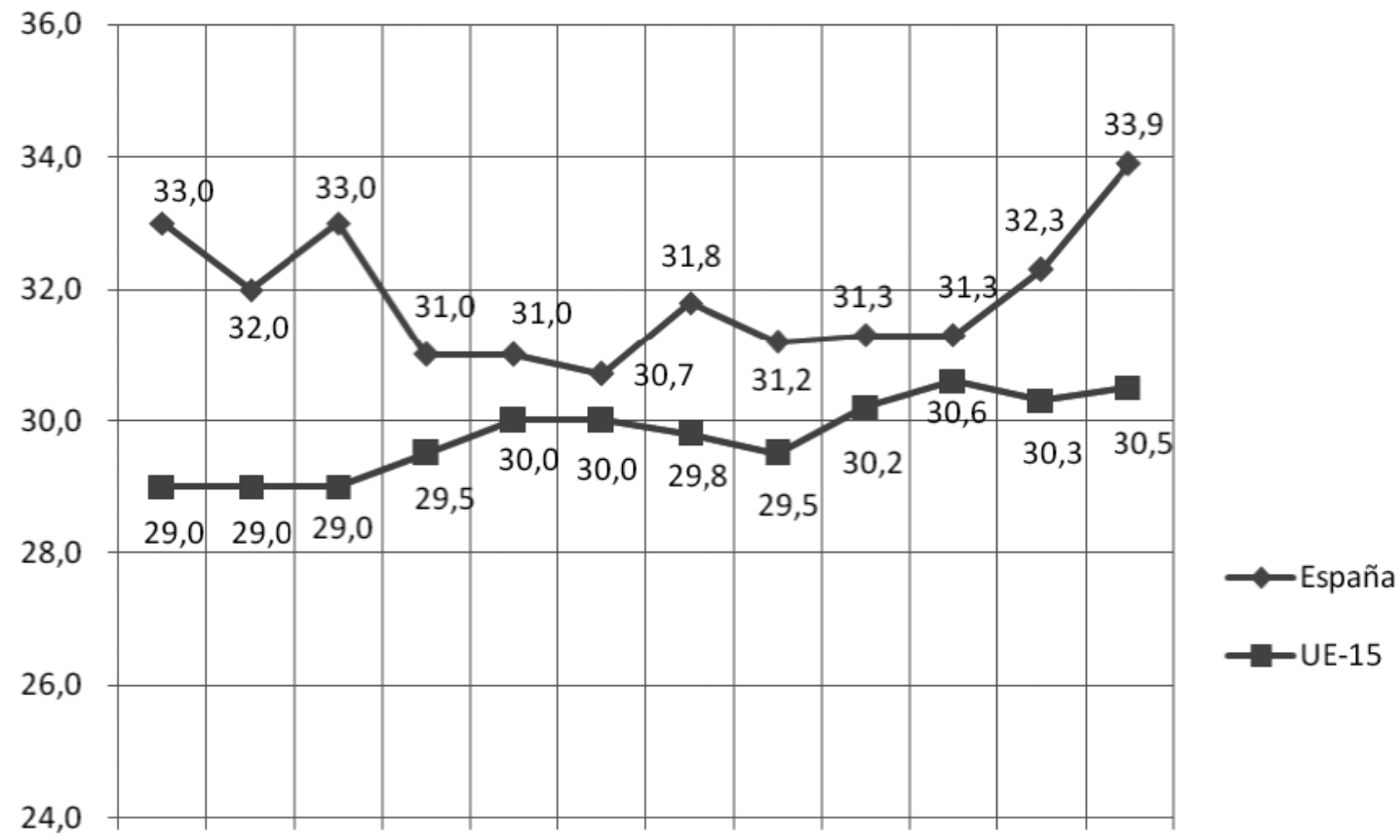

199920002001200220032004200520062007200820092010

Gráfico 1. Coeficiente de GINI (desigualdad). Fuente: Eurostat (2011).

nia tiene 29,3, y otros países centrales (datos de 2009) son: Francia con 29,8; Italia, con 31,5 y Reino Unido con 32,4; la UE-27 con 30,4. La media mundial es de 39 y países como Estados Unidos, Rusia, China, India o Brasil tienen un nivel de desigualdad superior a la europea. Los países europeos son los menos desiguales del mundo; es uno de los aspectos que definen el modelo social europeo y que se está cuestionando. En el otro extremo, los cinco países más desiguales son africanos (y los cinco siguientes latinoamericanos), llegando al máximo de 70,7 puntos en el caso de Namibia (Antón, 2009).

El gráfico 2 detalla el importante incremento, en estos últimos años, de la desigualdad en España, el país más desigual de la UE-15. La relación entre los ingresos del 20 por ciento de las personas con mayores ingresos y los ingresos del 20 por ciento con menores ingresos ha pasado de 5,3, el año 2007, a 6,0 el año 2009 y 6,9 , el año 2010. Es decir, la renta media del 20 por ciento de la población más pudiente es 6,9 veces superior a la renta media del 20 por ciento de la población más desfavorecida. Y existe una diferencia sustancial con la media (año
2009) de la UE-15 $(4,9)$ y la UE-27 (4,9). Países centrales son: Alemania $(4,5)$, Francia $(4,4)$, y Reino Unido e Italia $(5,2)$. Las trayectorias son divergentes, con apenas variación de la desigualdad europea y un pronunciado ascenso en España.

Igualmente, según la OCDE (2011) y para el año 2008, la brecha entre ricos y pobres en España (en este caso el número de veces que la renta media del 10 por ciento más rico supera la renta media del 10 por ciento más pobre) es 11,9 , la mayor de los veinticuatro países europeos miembros y una de las peores del total, cuya media es 9,6. Además, esta desigualdad de los países desarrollados se ha incrementado en más de una cuarta parte desde mediados de los años ochenta $(7,6)$, siendo la más alta de las tres últimas décadas.

El tercer indicador, para evaluar la intensidad protectora, es el gasto público social (Gráfico 3). España ha gastado en protección social, la pasada década, entre el 20 por ciento y el 21 por ciento del PIB, elevándose el año 2008 hasta el 22,1 por ciento y el año 2009 (último con datos disponibles) hasta el 25,0 por ciento. 


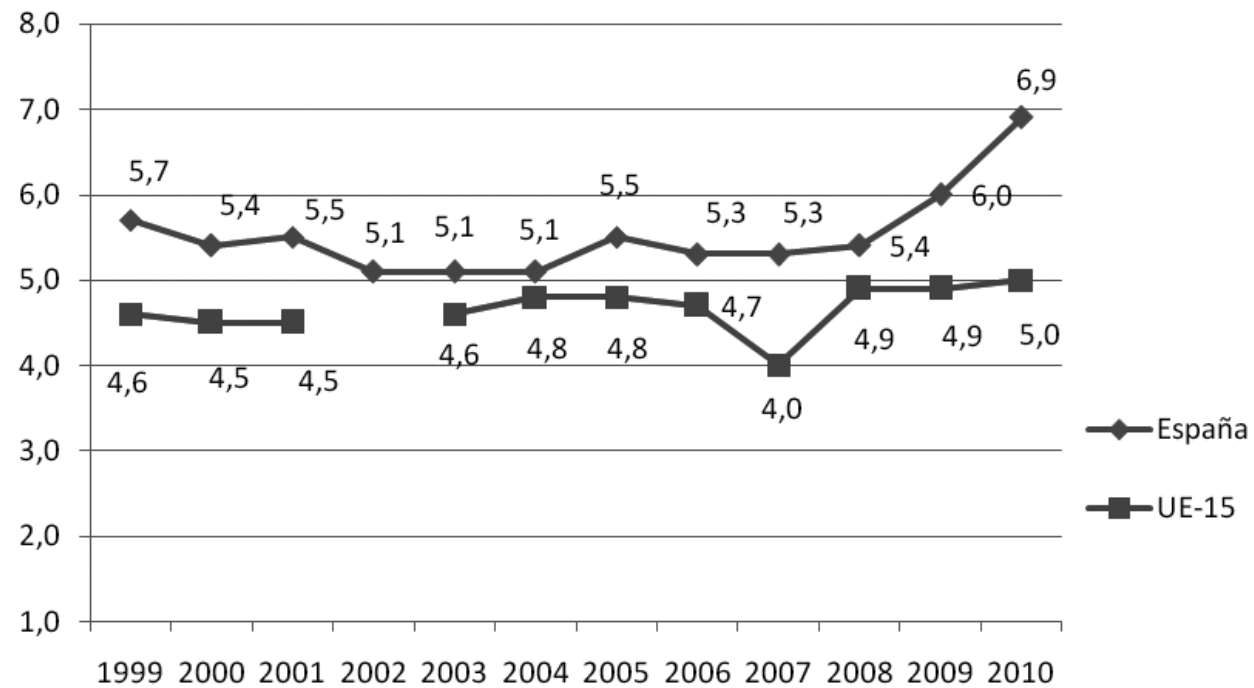

Gráfico 2. Ratio S80/S20. Fuente: Eurostat (2011).

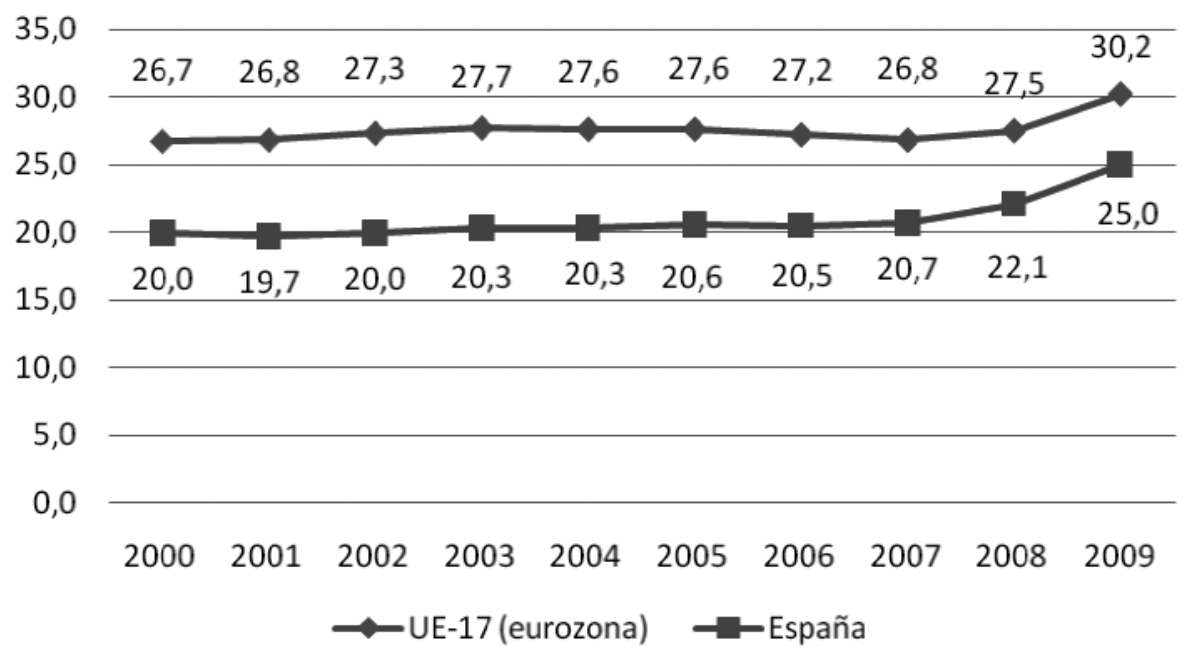

Gráfico 3. Evolución del gasto en protección social (porcentaje sobre el PIB). Fuente: Eurostat (2011).

Ese aumento está ocasionado, en gran medida, por el incremento de las prestaciones de desempleo, cuyo gasto ha llegado hasta tres puntos del PIB, con un diferencial de punto y medio superior a la media europea. No obstante, actualmente, su cobertura ha descendido hasta el 67,7 por ciento de los 4.420 .000 desempleados registrados, desde el 80 por ciento de mitad del año 2010, y la reducción es más significativa en el porcentaje (31 por ciento) que cubren las prestaciones contributivas que apenas alcanzan a 1.300 .000 personas (Ministerio de Trabajo, noviembre, 2011). De modo que, aunque constituye el 15 por ciento del gasto social total, más del doble que la eurozona $(6,8$ por ciento) y la UE-27 (6 por ciento), se reduce el porcentaje de la cobertura y la calidad de la protección a los desempleados.

Aún con ese importante incremento del gasto en protección al desempleo, en ese año 


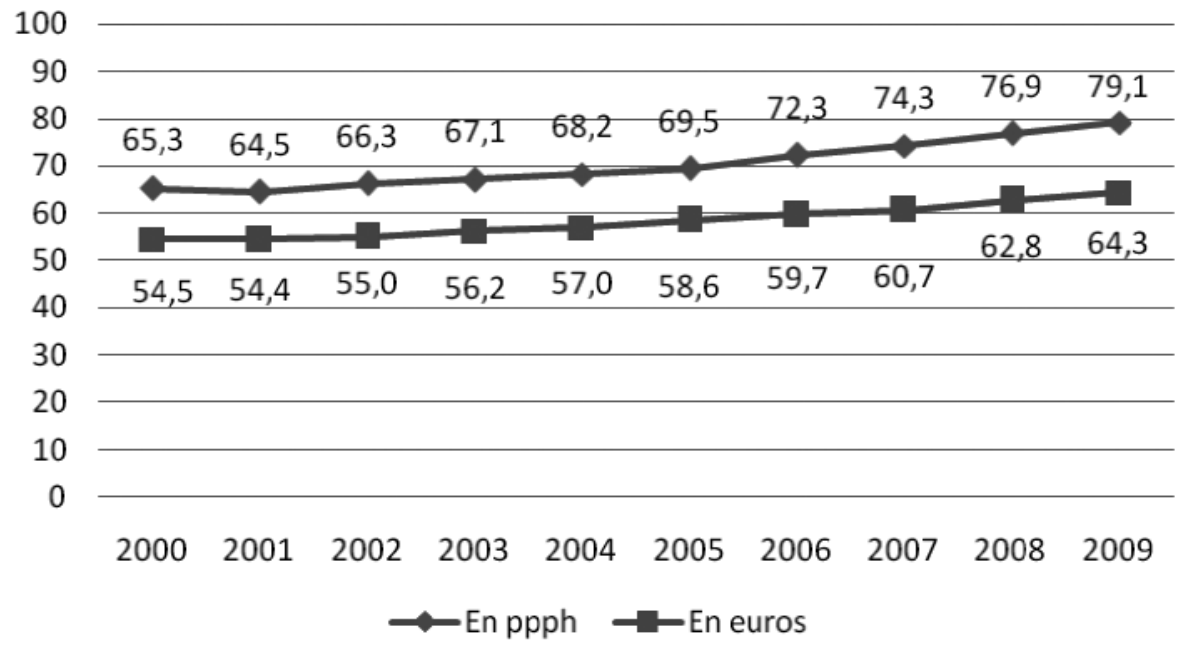

Gráfico 4. Porcentaje de gasto en protección social de España respecto de la eurozona. Fuente: Eurostat (2011).

2009, el esfuerzo público en protección social es muy inferior a la media europea. La diferencia durante ese periodo con la eurozona ha sido de unos seis puntos (más de 60.000.000.000 euros) rebajados en el último año hasta casi cinco. Respecto de la UE-27, cuyo gasto también aumenta casi tres puntos desde el año 2008 (26,7 por ciento) al 2009 (29,5 por ciento), la distancia es de cuatro puntos y medio.

La diferencia más significativa (unos tres puntos) es en el gasto en pensiones públicas: España, 10,1 por ciento del PIB y la eurozona 13,4 por ciento (UE-27, 13,1 por ciento). Es el mayor de todos y ha crecido ligeramente por el aumento de pensionistas y porque las nuevas pensiones son superiores a las que causan baja en el sistema. La distancia entre los porcentajes de gasto en sanidad pública en España (7,5 por ciento del PIB) y la UE-27 (9 por ciento) es de punto y medio, un 20 por ciento superior, aunque respecto del total del gasto en protección social ambos son similares (cerca del 30 por ciento) $)^{2}$.

En el año 2009, el gasto total en protección social por habitante en España es 4.412 euros, el 64,3 por ciento respecto de los 6.858 euros de la eurozona y el 71,1 por ciento de los 6.209 euros de la UE-27, habiendo aumentado lige- ramente en relación con los porcentajes respectivos de los años anteriores (gráfico 4). Y el gasto total en protección social, en paridad de poder de compra por habitante (ppph), en España es 6.087, el 79,1 por ciento respecto de la eurozona (7.695) y el 87,8 por ciento de la UE-27 (6.935). A lo largo de la década se ha producido un pequeño acercamiento respecto de la media de la eurozona, más pronunciado en los dos últimos años por el mayor gasto en protección al desempleo en España, que ha permitido recortar distancias en el total. No obstante, en el resto de funciones se mantienen las diferencias y lo relevante es que todavía el esfuerzo público por habitante es muy inferior a las medias europeas.

Los años de alto crecimiento económico, hasta el año 2007, no se aprovecharon en España para incrementar el porcentaje del PIB dedicado a protección social (inferior al 21 por ciento) y acercarnos a la media europea (en torno al 27 por ciento). El PIB iba creciendo más que la media europea. El total del gasto público social también ha aumentado respecto de los años anteriores; pero no se ha superado ese fuerte déficit de servicios públicos y prestaciones fundamentales — pensiones, sanidad, servicios sociales - hacia una distribución

\footnotetext{
${ }^{2}$ Otro gasto público significativo, aunque no contabilizado en protección social, es en educación (4,62 por ciento), inferior a la media de la UE-27 (5,07 por ciento) (datos de Eurostat-2011 para el año 2008), aunque según el Ministerio de Educación (2011) alcanza (sin gastos financieros) el 5,02 por ciento para 2009.
} 
más equitativa. Esa pequeña ampliación del gasto social por habitante tampoco se asentaba en una estructura fiscal progresiva sino en ingresos extraordinarios de la burbuja inmobiliaria. Desaparecidos estos, con la recesión del año 2009 y ante la fuerte crisis del empleo y la ampliación de necesidades protectoras, en vez de ampliar los ingresos, se impone la política de austeridad del gasto público.

Por tanto, esa expansión es insuficiente y no deriva de la existencia de nuevas políticas sociales progresivas, sino de derechos sociales adquiridos de protección al desempleo (junto con un punto más del PIB para pensiones), que funcionan como «estabilizadores automáticos». Las dos medidas más relevantes de refuerzo protector - ley de dependencia y subsidio semestral de 400 euros para parte de desempleados - tienen un impacto presupuestario limitado, incluso con riesgo de reducción de su cobertura. La ausencia de una política social y distributiva más consistente y progresiva, a pesar de la etapa más prolongada de fuerte crecimiento económico en España, no ha permitido superar la debilidad comparativa de nuestro Estado de bienestar.

Además, entre los años 2001 y 2007, en España se ha producido un significativo aumento poblacional, con una de las tasas de variación (16-18) más elevada, debido a la fuerte inmigración, frente a la media de la UE27 (4-5); aunque ese alto crecimiento, más del triple que el europeo, se ha desacelerado desde entonces acercándose a la media europea. La indicada expansión demográfica contribuyó al incremento del empleo y la riqueza creada, pero también supuso nuevas necesidades sociales, cuya cobertura pública ahora es contenida.

En definitiva, la limitación del porcentaje del PIB, dedicado a gasto público en protección social distinto al desempleo, ha supuesto que cada habitante reciba un porcentaje insuficiente de la riqueza creada. Con similar proporción de recursos respecto del PIB, servicios públicos fundamentales - sanidad, educación, servicios sociales - han tenido que afrontar necesidades de un incremento relevante de la población, cuya consecuencia ha sido la reducción de su calidad. Es decir, respecto de la riqueza generada, se modera ese esfuerzo público relativo per cápita, se limita la intensi- dad protectora pública y se consolida la gran distancia con la media europea (que también sufre medidas de contención de gasto). Así, en euros no llega al 65 por ciento en relación con la eurozona (ni al 80 por ciento en ppph). Ese déficit protector se acentúa al considerar la excepcionalidad de la protección al desempleo y los límites de su cobertura, ya que su imprescindible aumento actual no consigue equilibrar la fuerte desprotección y las crecientes necesidades y desigualdades, derivadas de un paro prolongado y masivo, el doble que en la UE27. Ese resquebrajamiento del contrato social, de la protección pública básica, y las dificultades económicas de la mayoría de familias (61 por ciento según el CIS-2011), genera profundas incertidumbres y graves problemas para la cohesión social (Laparra y Pérez, 2011).

\section{Cambios regresivos y segmentación de la política social}

Los hechos analizados expresan los déficit del Estado de bienestar en España, su debilidad comparada con los países europeos de nuestro entorno y su fragilidad para atender las necesidades y garantías de protección social de la población, puestas más de manifiesto ante la mayor gravedad de las consecuencias sociales de la crisis. A partir de esa valoración, ahora se profundiza en el sentido regresivo y segmentado que expresan los cambios de las políticas socioeconómicas. Se completa y fundamenta su interpretación, considerando los análisis empíricos y teóricos propios desarrollados en otras investigaciones recientes. Entre la literatura comentada en ellas se pueden destacar: Navarro (2007) y Rodríguez Cabrero (2004). Y se hará referencia a diversos análisis.

Frente a la persistencia de la crisis socioeconómica y del empleo, que dura ya cuatro años, en la Unión Europea, particularmente desde el Consejo Europeo de mayo de 2010, se ha consolidado una política liberal-conservadora, dominante entre las élites institucionales europeas, con las siguientes características (Antón, 2011; Krugman, 2009; Navarro et al., 2011). El problema central sería el déficit público y la deuda (soberana), no la contracción económica ni el paro masivo. Sus principales medidas no van dirigidas directamente a la reactivación económica y de empleo. Su prioridad es la «consolidación fiscal» como garantía del cum- 
plimiento de los Estados y agentes económicos de sus compromisos con los acreedores financieros, la devolución de las deudas contraídas por el masivo endeudamiento (privado y financiero, y luego público). Impulsa medidas de ajuste y austeridad (para las capas populares), con cambios regresivos del Estado de bienestar y deterioro de derechos sociolaborales. Supone, particularmente en países periféricos como España, prolongación de la crisis y reparto desigual de sus costes (en cada sociedad y entre países). En el plano sociopolítico refuerza el desequilibrio en las relaciones de poder, con una fuerte hegemonía conservadora en los países europeos centrales y las instituciones de la Unión Europea: mayor dominio de los poderes económico-financieros y empresariales; mayor subordinación de las clases trabajadoras, y debilitamiento de fuerzas progresistas, de izquierda y el sindicalismo.

La interpretación liberal-conservadora dominante ofrece apariencia «técnica» o neutral, aunque sea ideológica y no realista, y solo es funcional para los «poderosos» (y algunas capas medias/altas ascendentes). Ese discurso pretende diluir responsabilidades de sus gestores institucionales: «la culpa es de todos o de nadie»; «las consecuencias sociales son neutras e inevitables». Trata de asegurar la continuidad de las políticas neoliberales y una salida conservadora a la crisis. Intenta salvar cierta «cohesión social», aunque frente al descontento social, su versión más autoritaria pone el acento en el control social y la imposición normativa.

Esta orientación, ante la escasa legitimidad social de la política de recortes sociales, busca afianzar a los «poderosos» y relegitimar a las élites políticas y gestoras. Apuesta por un nuevo reequilibrio de poder y de acumulación de riqueza, junto con el retroceso de condiciones y derechos sociolaborales y la protección social pública. Intenta justificar los planes de austeridad, la socialización de pérdidas (financieras), la prolongación de la crisis y los desequilibrios en la Unión Europea.

Las reformas en distintos países tienen particularidades. No obstante, el proceso se puede definir como cambio cualitativo, fundamentalmente regresivo. No hay un desmantelamiento inmediato y generalizado del Estado de bienestar, aunque haya presiones relevantes hacia ello. Tampoco se mantiene el status quo anterior, y menos hay una mejora global. Las características principales de esa reestructuración son tres: 1) contención del gasto públicosocial, con limitación del esfuerzo público en relación al PIB - per cápita y recorte de los derechos sociales, particularmente del sistema de pensiones; 2) «racionalización», reajustes globales regresivos de derechos sociolaborales y diversas adaptaciones - neutras o mejoras parciales_-; 3) incremento de la diferenciación interna, con mayor segmentación institucional y de la calidad de los servicios públicos, junto con el desarrollo de privatizaciones parciales. Supone adaptar las políticas sociales a la segmentación laboral y de rentas y a la fragmentación social, y una transformación institucional hacia sistemas mixtos, públicos y privados (Rodríguez Cabrero, 2004).

Las transformaciones no son sólo en la esfera económica y laboral o en la orientación ideológica liberal de las políticas económicas. Esos aspectos, los primeros y más desarrollados, condicionan el sentido de los cambios específicos de las políticas sociales. Así, se subordinan a esos imperativos económicos que aparecen como incuestionables. Los mecanismos públicos de bienestar se adecuan a las desigualdades socioeconómicas y laborales existentes. La tendencia dominante es su continuada reestructuración institucional, particularmente defendida por los grandes poderes económicos. Conservan una parte básica de su función social, pero disminuye su intensidad protectora pública respecto de derechos anteriores, e incluyen componentes de «adaptación» o racionalización.

El debilitamiento de la calidad de esos servicios públicos o la limitada intensidad protectora de las prestaciones públicas, aunque se mantengan todavía los derechos subjetivos universales, facilita la ampliación de mecanismos privados para compensar las insuficiencias de seguridad pública. Ante esa fragilidad de garantías y coberturas de los sistemas públicos, constituye una salida para las capas acomodadas con capacidad financiera de un esfuerzo adicional. Una de las consecuencias de ese proceso es la ruptura de la confianza ciudadana en los sistemas públicos, el distanciamiento de una parte de sus bases sociales, las clases medias (las capas altas ya confiaban 
en mecanismos privados), cuya actitud es más ambivalente: menos impuestos y una adaptación al deterioro público con más inversión privada y cobertura complementaria. No obstante, el apoyo ciudadano a los principales mecanismos públicos de bienestar todavía es muy alto y ronda los dos tercios de la población (Arriba et al., 2006; Noya, 2004).

Existen básicamente dos ideas-fuerza y la pugna social, cultural y política entre ellas es profunda y persistente. La primera, dominante en la esfera institucional y defendida por los grandes poderes económicos y políticos, considera el desarrollo del mercado como la palanca principal para resolver la cuestión social. Las políticas sociales deberían estar subordinadas al crecimiento económico $y$, ahora, con la crisis económica y el paradigma de la disminución del déficit público y la deuda pública — sin ampliar los ingresoshabría que contener su financiación, reducir el esfuerzo público previsto. La segunda, con importante apoyo popular y legitimación social, defiende la consolidación y el avance de las políticas públicas y sociales; su punto de referencia son las «necesidades» de la sociedad, las clásicas garantías públicas frente a los riesgos sociales (enfermedad, vejez, paro, etc.). Siguen constituyendo «demandas ciudadanas» de cobertura de protección social pública suficiente en un contexto económico de mayor riqueza que cuando se consolidaron los Estados de bienestar europeos.

Dentro de la relativa ambigüedad del concepto de «modelo social europeo», como pacto y equilibrio entre posiciones liberales y socialdemócratas, la orientación dominante va hacia un tipo de Estado de bienestar «débil»: cumplir funciones mínimas de protección y seguridad, a través de algunos servicios públicos universales pero básicos, para asegurar la cohesión social. Es el campo ideológico del «liberalismo social» predominante en los países centrales y las instituciones de la Unión Europea. Se debilita la función redistributiva del Estado, especialmente la «vertical» hacia abajo, tanto en el plano de los ingresos (menos impuestos, especialmente los progresivos) como en el del gasto (contención del gasto social e incremen- to de desgravaciones a empresas y rentas medias-altas).

En definitiva, frente a la reestructuración regresiva del Estado de bienestar, la mayoría de las sociedades europeas, aunque con diversas ambivalencias y segmentaciones, expresa sus preferencias por una fuerte protección social y unos servicios públicos de calidad (Eurostat, 2011) ${ }^{3}$. Es impresionante el bloque de los «poderosos» que trata de imponer ese retroceso de los derechos socioeconómicos; pero la opinión ciudadana por garantizarlos es profunda y persistente. La actitud democrática de esas mayorías sociales, aun cuando la expresión electoral e institucional sea distinta, está condicionando el ritmo y la generalización de los recortes sociales.

En el plano cultural hay una reorientación hacia un «modelo intermedio», de tipo socialliberal, con equilibrio inestable entre un Estado social de mínimos, según el postulado neoliberal, y la inercia institucional de los mecanismos clásicos, continentales o socialdemócratas. Los discursos institucionales dominantes buscan el debilitamiento de la cultura y los derechos asociados a la ciudadanía social y laboral, para diluir esa resistencia ciudadana a las políticas regresivas. La consecuencia práctica de los reajustes de las políticas sociales es el deterioro de la integración social y la vertebración de las sociedades, con evidentes riesgos de mayores brechas sociales, menor cohesión social y dificultades para la convivencia intercultural. El resultado de la presencia de ambas fuerzas y dinámicas, al menos a corto plazo, es ese retroceso significativo del Estado de bienestar, aunque no su destrucción inmediata. Ello significa: deterioro de la calidad e intensidad protectora de los principales mecanismos del Estado de bienestar y, al mismo tiempo, continuidad de ciertas funciones de protección social, instituciones y formas de intervención públicas, con unas garantías básicas de carácter universal y el desarrollo de sistemas privados y mixtos.

La sociedad, atendiendo al estatus socioeconómico, se puede dividir en tres tercios. La reestructuración institucional, con el deterioro de servicios y prestaciones públicos y la pro-

\footnotetext{
${ }^{3}$ Véase Eurobarómetro $n^{\circ} 74$, realizado en noviembre de 2010 y publicado por Eurostat en enero de 2011.
} 
moción de sistemas privados o complementarios, adapta mecanismos mixtos para el tercio superior. El reequilibrio es mayor cobertura privada, hasta dejar la pública como complementaria. Para los otros dos tercios, intermedio e inferior, los sistemas públicos son los principales (con algún complemento privado secundario) o exclusivos.

Esa adaptación a la segmentación se corresponde con la diferenciación de los consensos fundamentales. Ese proyecto social «intermedio», con segmentación de la protección, es frágil y sus fronteras son inestables. La apuesta liberal del Estado asistencial y de mínimos establece unas garantías públicas básicas para la supervivencia del tercio inferior, mientras debilita calidad e intensidad de las coberturas públicas. Éstas son limitadas pero todavía suficientes para garantizar una protección sustancial al tercio intermedio, al que se pretende forzar hacia un esfuerzo privado adicional, si quieren mantener similar protección. El horizonte ofrecido es la relativa inseguridad y la débil protección pública, su desenganche de esas instituciones públicas y su desplazamiento cultural y práctico hacia mecanismos privados o mixtos. Es evidente en ámbitos donde el esfuerzo suplementario por el servicio privado (o concertado) no es muy elevado. Por ejemplo, en el caso de la enseñanza, aunque a nivel estatal la escuela pública sigue acogiendo a unos dos tercios de alumnos, en las grandes ciudades y sus cinturones metropolitanos (Madrid, Barcelona, etc.), ambas redes, pública y privada-concertada están presentes al cincuenta por ciento.

Además, durante la última década, se han incrementado las necesidades educativas (importante inmigración, persistencia de fracaso escolar) con una sobrecarga para la escuela pública y sus docentes. Sin el suficiente apoyo institucional a la red pública y ante el temor, muchas veces injustificado, a las dificultades para el ascenso social de sus hijos, se pretende ampliar la «demanda» de ese sector intermedio (la mayoría de capas medias-altas ya se ha trasladado), de mayor red privada-concertada con fondos públicos y un coste adicional particular limitado y permisible con cierto esfuerzo.
Sobre esa dinámica, con importantes intereses materiales e ideológicos de la Iglesia católica, es donde se refuerzan las políticas de ajuste en la educación, que añaden mayores requerimientos al profesorado y menores garantías de calidad educativa de la escuela pública, y que han generado la fuerte indignación de profesores y familias en Madrid y otros territorios. El riesgo es una escuela pública deteriorada para el segmento inferior, ya constatable en muchos barrios, y la consolidación de la fractura social y la desigualdad de oportunidades, junto con la correspondiente frustración docente.

No obstante, ese sistema de «conciertos» con una financiación pública fundamental y una fuerte segmentación, según estatus socioeconómico y origen étnico, y esos servicios públicos sólo para componentes del tercio inferior es bastante excepcional del campo educativo. En otros dos ámbitos fundamentales por dimensión del gasto — sanidad y pensiones públicas - las prestaciones e instituciones públicas, aún con gestión privada, son comunes a los distintos segmentos de la población. La diferenciación no viene tanto por la «separación» de la población en sistemas diferentes cuanto por el deterioro de la calidad de la asistencia pública y una cobertura «complementaria», con esfuerzo privado adicional, de determinados servicios o complementos.

La reducción del gasto público previsto afecta, sobre todo, al sistema público de pensiones, con la principal reforma social, aprobada en febrero de 2011. Según el propio Gobier$\mathrm{no}^{4}$, supone una fuerte rebaja de 3,5 puntos del PIB - unos 35.000 millones de hoy - la cuarta parte del gasto previsto, cuando a todos los pensionistas existentes en el sistema se les haya aplicado la reforma, en el año 2050. Según cálculos propios (Antón, 2011), respecto de los actuales derechos, la reducción de la cuantía mensual media de las pensiones públicas futuras alcanza un 20 por ciento, con una distribución desigual según diversos colectivos. En los planos económico y social ese acuerdo no satisface duraderamente a los mercados, no crea empleo, la mayoría ciudadana lo percibe como un recorte social y no sirve para remontar la escasa legitimidad de la política

${ }^{4}$ Comunicado por la Vicepresidenta Salgado en la Comisión del Pacto de Toledo del día 10 de febrero de 2011, sólo una semana después de la firma del acuerdo social. 
gubernamental (Barómetro del CIS, marzo, 2011).

Los efectos de esa reforma son dobles: por un lado, una menor intensidad protectora del sistema público de pensiones respecto de los derechos anteriores, con deterioro general de la calidad de vida en la vejez. Por otro lado, una incentivación para el desarrollo de los fondos privados de pensiones, al forzar a sectores acomodados y que pueden permitírselo a una inversión adicional, si quieren mantener similar protección en el futuro, y así estimular el negocio del sistema financiero.

En Sanidad se tiende hacia la ampliación del copago - Cataluña - existente en el gasto farmacéutico, la eliminación de determinados servicios y la menor calidad de la asistencia ambulatoria y hospitalaria por una mayor presión ejercida hacia el personal sanitario y otros servicios.

En atención y cuidado de las personas, dada la escasez de servicios públicos (por ejemplo, residencias de ancianos o escuelas infantiles de 0 a 3 años), las opciones son: esfuerzo privado para resolver la asistencia por la vía del mercado o, para la mayoría, la sobrecarga y la responsabilidad se traslada a la familia, a las mujeres en concreto. Respecto a los Servicios Sociales, muy particularizados y fragmentados $\mathrm{y}$, en general, para personas y grupos desfavorecidos, la presión es más fuerte hacia su «asistencialización» y el control del «consumo» de servicios y prestaciones. Ante necesidades más amplias, quedan muy insuficientes mecanismos como los planes de inserción, las rentas básicas o mínimas; incluso, las prestaciones por desempleo tienen cada vez menos cobertura protectora. Las medidas de integración social e inserción laboral, en vez de apoyo complementario a las prestaciones monetarias, son utilizadas muchas veces como instrumentos selectivos del acceso a los derechos (Antón, 2003).

Algunos sistemas privados pueden ser funcionales para las capas acomodadas; pero gran parte de esas personas exigen unos servicios públicos y unas prestaciones sociales suficientes, no mínimos que puedan «complementar» con un esfuerzo adicional limitado. Buscan diferenciación, garantías suplementarias y «calidad» para ellos, pero a un coste relativo pequeño, como en la enseñanza. Sobre todo, para sectores intermedios e inferiores, es un sobrecoste difícil de asumir, especialmente en tiempos de incertidumbre económica, de mayores necesidades sociales y menor poder adquisitivo.

En definitiva, se produce una fuerte segmentación de la protección social. Ante la insuficiente intensidad protectora pública, responsabilidad institucional y solidaridad colectiva, se produce la trampa del traslado de la responsabilidad protectora a la familia (la mujer), el individuo o la «sociedad civil» (Tercer Sector). Hay riesgo de desarrollar, por un lado, el «asistencialismo» de sectores vulnerables y, por otro lado, el mercado para capas acomodadas. Las consecuencias que derivan son: dilución de los derechos «contributivos», deterioro de los servicios públicos de calidad, incertidumbre e inseguridad para las clases «trabajadoras» (intermedias) y riesgo de exclusión social para las capas bajas.

La opción ciudadana mayoritaria sigue exigiendo empleo decente, particularmente juvenil, y servicios públicos de calidad ${ }^{5}$. Y cobran mayor relieve las políticas de cohesión social y la convivencia intercultural, con una dinámica integradora de la inmigración. Los procesos de deterioro de los servicios públicos, con consecuencias de menor protección y seguridad social para la mayoría de la población, tienen dificultades para conseguir legitimidad social.

Existe una importante desconfianza ciudadana en las élites políticas actuales, derivada de su gestión frente a la crisis con medidas impopulares de recortes sociales y sin solucionar el grave problema del paro ni la incertidumbre socioeconómica. La clase política aparece, en los últimos Barómetros del CIS (desde julio de 2010), no como la solución sino como el tercer gran problema de la sociedad, tras el paro y las incertidumbres económicas.

La disociación entre la opinión de la ciudadanía y las decisiones de las grandes instituciones también es evidente, en la reforma social estructural más significativa de los últimos tiempos: el sistema de pensiones. Ha contado

\footnotetext{
${ }^{5}$ Véase Eurobarómetro $n^{\circ} 74$, realizado en noviembre de 2010 y publicado por Eurostat en enero de 2011.
} 
con el apoyo del Gobierno, el 90 por ciento del arco parlamentario, las organizaciones empresariales y las direcciones de los grandes sindicatos. A pesar de un aval institucional tan impresionante y los intentos machacones en los grandes medios de comunicación de justificar esa reforma como positiva para la protección social de trabajadores y trabajadoras, la opinión ciudadana mayoritariamente lo considera un retroceso y muestra su disconformi$\mathrm{dad}^{6}$. En consecuencia, derivado de sus medidas de recortes sociales, se amplía el grave problema de legitimidad social que tiene el Gobierno y la clase política, particularmente el PSOE, que ha perdido más de cuatro millones de votos en las elecciones generales del 20 de noviembre de 2011.

En conclusión, según las fuentes citadas, en España existe un gran respaldo a un Estado de bienestar más protector, superior al 70 por ciento, especialmente a la sanidad, enseñanza y pensiones públicas. Al mismo tiempo, existe amplia percepción (50 por ciento) de importantes déficits en esos servicios públicos, y se rechazan los recortes sociales por el 80 por ciento. No obstante, hay diferencias significativas por la variable de clase social: entre las clases alta y media-alta ese apoyo es algo inferior; existen minorías significativas (entre el 20 por ciento y el 30 por ciento) que defienden opciones mixtas o privadas. Además, existe una profunda desconfianza en la clase política para gestionar los asuntos públicos, particularmente la política social y de empleo.

Para gran parte de la ciudadanía es evidente el dominio de los grandes poderes económicos, con subordinación de la democracia y la sociedad, y el carácter injusto de la política de austeridad. Los discursos oficiales han querido justificar los recortes sociales con el argumento de «contentar» a los mercados financieros. Los sacrificios exigidos a la población se presentaban como leves, transitorios e imprescindibles para una pronta recuperación económica y de empleo. La realidad y la percepción ciudadana mayoritaria es que persiste la crisis y se agravan sus consecuencias sociales, esos sacrificios no han sido equilibrados, sus causantes y responsables no asumen ningún coste y se vuelve a descargar en las propias capas populares. De ahí que sea poco creíble el discurso oficial de la bondad de un esfuerzo (popular) adicional y transitorio para un fin supuestamente próximo de mejora y bienestar. Ni tampoco goza de gran credibilidad la idea de que la política sociolaboral mejora y favorece la situación de la mayoría de la sociedad. En una amplia conciencia social se instala la indignación por una dinámica socioeconómica y unas reformas estructurales valoradas como causantes de retroceso social e incertidumbre vital. Se consolida una fuerte disociación entre una significativa opinión ciudadana progresista y la orientación regresiva dominante de las políticas sociolaborales, en un plano social distinto al electoral y a la hegemonía conservadora en las principales instituciones políticas.

\section{Fundamentos de los servicios públicos y perspectivas de la reforma social}

Tras esta interpretación de las políticas sociales y su legitimidad, se expondrán diversos interrogantes y reflexiones que faciliten la discusión sobre las respuestas a los retos presentes.

Ante los desequilibrios del contrato social en una sociedad fragmentada, se vuelven a abrir nuevos debates sobre los fundamentos institucionales, normativos y teóricos de los servicios públicos, y el papel de las políticas sociales. Expresa adecuación, conflicto y renovación entre valores distintos y una nueva configuración e interrelación de diferentes dinámicas sociales e institucionales. En el artículo se sintetizan algunas ideas desarrolladas en otra parte. Primero, los reequilibrios entre derechos y deberes, con el valor de la «reciprocidad». Segundo, la combinación entre meritocracia (contributividad), equidad e igualdad. Tercero, el sentido de la justicia social o bien la dinámica de igualdad de oportunidades («débil» o «fuerte»), con la transformación de las desigualdades de origen y el entorno, los privilegios (de los de arriba) y las garantías de una plena ciudadanía social y laboral. Cuarto, la tensión entre igualdad y libertad, ampliando la participación democrática y disminuyendo el burocratismo, así como reforzando e inte-

${ }^{6}$ Véase la encuesta de Demoscopia, El País, 6-2-2011, y el Barómetro del Centro de Investigaciones Sociológicas - CIS — de marzo de 2011, publicado el 5-4-2011. 
grando los derechos individuales y los colectivos, ya que la persona tiene un doble componente: individual y social. Quinto, el refuerzo de lo público (regulación, servicios, prestaciones), junto con la descentralización institucional, la participación ciudadana y la conveniencia de un significativo Tercer Sector. Sexto, el equilibrio entre la «universalidad» de los derechos (a todos igual frente a la discriminación) y la «redistribución igualitaria» (compensatoria de las desigualdades privadas, y gravosa para los poderosos).

El modelo social europeo se viene reinterpretando con un contenido cada vez más liberal, con mayor protagonismo del mercado para resolver la cuestión social y debilitando sus rasgos más igualitarios, participativos y solidarios. Las instituciones europeas ponen el énfasis en la responsabilidad y la activación individual como justificación para diluir los derechos adquiridos y controlar socialmente a los sectores inactivos y precarios (con derechos a protección). La solidaridad hacia los sectores débiles, la acción compensadora y una redistribución más justa se intentan neutralizar con una cultura de apariencia universalista - el trato igual ante necesidades desigualesque asegure la reproducción de las segmentaciones socioeconómicas y los privilegios de estatus. La igualdad de oportunidades se torna «débil», la base común es mínima y hace abstracción de las desigualdades de origen y trayectorias y el contexto (Judt, 2010).

En una sociedad más fragmentada, con distintos riesgos y necesidades sociales, y con mayores discontinuidades en la intensidad y duración de las aportaciones individuales (deberes cívicos y de empleo, cotizaciones sociales e impuestos) es más difícil establecer la correspondencia de los derechos y fortalecer la equidad respecto del objeto a proteger. La reciprocidad entre derechos y deberes es fundamental como base del contrato social. La meritocracia, la proporcionalidad de las recompensas respecto de los méritos individuales, es más justa que otros tipos de distribución de posiciones sociales basados en privilegios o desigualdades previas, de origen, estatus o propiedad. Es el criterio dominante en el ámbito educativo o en algunas prestaciones sociales, como las pensiones contributivas; pero es limitado para abordar todas las necesi- dades sociales desde una igualdad más fuerte y una dinámica integradora y solidaria. La aplicación restrictiva o liberal de la estricta proporcionalidad, como compensación exclusiva según lo aportado individualmente, es insuficiente. Rompe la cultura de los derechos universales, especialmente intensa en ámbitos como la sanidad y la acción contra la pobreza y la exclusión social. Por tanto, la reciprocidad, la combinación de derechos y deberes, hay que reinterpretarla y adecuarla, con una dimensión colectiva, de equidad y justicia social, y contemplando el conjunto de la dinámica social, los riesgos colectivos y todo el ciclo vital y generacional (Antón, 2005).

El llamado «pluralismo» de los sistemas de protección tiene un carácter ambivalente. Para definir mejor su sentido hay que establecer su relación con la desigualdad socioeconómica y la segmentación de la seguridad y la protección social. Existe un conflicto entre igualdad, responsabilidad colectiva, institucional y social, y «libertad de elección» (Antón, 2009). El pluralismo puede permitir mejorar o reforzar la protección y seguridad frente al Estado burocrático, o bien promover menor protección pública y su segmentación, con inseguridad para capas populares. Está clara la conveniencia del reforzamiento democrático y la eficiencia organizacional, no el poder adquisitivo del usuario, frente a la jerarquía y los privilegios burocráticos.

En resumen, mi propuesta normativa es más y mejor Estado «social», defensa de lo público como garantía fundamental y provisión principal de servicios públicos y prestaciones sociales, junto con mayor participación democrática, descentralización, desburocratización y eficiencia de sus recursos; y todo ello, combinado con la acción asistencial y solidaria del Tercer Sector y la coexistencia y regulación de las actividades «complementarias» privadas y de mercado.

Existen grandes interrogantes para el futuro de la reforma social: ¿dimensión de las nuevas brechas sociales y los problemas de cohesión social y convivencia intercultural? ¿qué modernización económica y cambio tecnológico con nuevos marcos de regulación socioeconómica y laboral? ¿y la sostenibilidad medioambiental? ¿qué expresión política, electoral y asociativa de la ciudadanía? ¿indi- 
vidualización, fragmentación, desafección? En particular, existen incógnitas en dos aspectos sociopolíticos importantes: ¿qué nuevos proyectos y teorías del cambio social son necesarios? ¿declive o renovación y regeneración de la socialdemocracia, de las izquierdas sociales y políticas? (Judt, 2011; Sevilla, 2011; Touraine, 2011).

Contamos con algunos valores centrales en la tradición progresista, necesitados de impulso y renovación: igualdad, libertad, solidaridad, laicidad, democracia. En referencia a la política social y frente a la interpretación liberal y conservadora, hay que poner el énfasis en un enfoque «social». Sus ejes centrales pueden definirse de forma siguiente: lo relevante es el objetivo ético y sociopolítico de la igualdad social, la participación cívica y la democracia social y económica avanzada; el horizonte debe ser el cambio de la política socioeconómica dominante y una orientación progresista de las instituciones estatales, europeas y mundiales; vigencia y refuerzo del Estado de bienestar y el modelo social europeo; importancia de la plena ciudadanía social y laboral, la integración social y la convivencia intercultural. Por tanto, la solución es un nuevo papel de la política (Arias y Costas, 2011) y la sociedad. La prioridad son las personas y no los mercados. Ese sustrato cultural tiene una amplia legitimidad social en Europa, aun con la fragmentación de las capas populares y la debilidad de las izquierdas.

La reforma social se desarrollará entre tres dinámicas: las inercias de las actuales instituciones del Estado de bienestar; los constreñimientos económicos y políticos de la mundialización, y el curso de los conflictos sociales y políticos en torno a las políticas sociales del futuro (Rodríguez Cabrero, 2004). Existe una hegemonía política conservadora en las instituciones europeas y los principales países, junto con relativo desconcierto y perplejidad de las izquierdas. No aparecen sujetos sociales consistentes para asegurar un cambio global progresista e inmediato, pero esa ciudadanía crítica es un factor de freno a la involución y estímulo para la transformación. Los condicionantes son: la gestión de la crisis socioeconómica y la pugna social y democrática por el tipo de salida. Se ventila la consolidación de las políticas de ajuste y austeridad con contención del gasto público social y estancamiento económico y del empleo, o bien, la reorientación hacia una salida más equilibrada y con mayor cooperación y solidaridad en el marco europeo.

Estamos ante un nuevo ciclo histórico, en particular, para la política social. ¿Hasta dónde los sectores progresistas pueden desarrollar una dinámica activa, expresar un horizonte de cambio más igualitario y solidario, renovar los discursos y configurar un «reformismo fuerte» y progresivo? Conviene plantearse interrogantes y aventurar respuestas basadas en elementos existentes para configurar ese proyecto. Primero, ¿qué vale de la tradición?: vigencia de valores «progresistas», convenientemente renovados, igualdad, libertad, solidaridad, laicidad, democracia. Segundo, ¿qué modelo social?: refuerzo de las bases de la ciudadanía social y laboral, sociedad democrática, convivencia intercultural y regulación pública. Tercero, ¿es posible una democracia social y económica más avanzada para la próxima década? y ¿qué horizonte transformador? No hay que descartarlo, pero depende del dinamismo sociopolítico con renovados sujetos y élites sociales.

Desde el campo social de la aspiración a una sociedad más justa y solidaria, la conclusión normativa es sencilla, aunque difícil de articular: necesidad de un nuevo pensamiento social más crítico, importancia de una ciudadanía activa y una acción social basada en la igualdad.

\section{Referencias bibliográficas}

Antón, A. (2003). Rentas básicas y nuevo contrato social. Madrid: GPS-Fundación Sindical de Estudios.

Antón, A. (2009). Reestructuración del Estado de bienestar. Madrid: Talasa.

Antón, A. (julio, 2010). La educación ante la crisis: una reflexión crítica. [On line]. Disponible en: http://www.pensamientocritico.org

Antón, A. (2011). Resistencias frente a la crisis. De la huelga general del 29-S al movimiento 15$M$. Valencia: Germanía. 
Antón, A. (coord.) (2005). Rentas básicas y protección social, Cuaderno de Relaciones laborales 23(2).

Antón, A. (coord.) (2010). La reforma del sistema de pensiones. Madrid: Talasa.

Arriba, A., Calzada, I. y Pino, E. del (2006). Las actitudes de los españoles hacia el Estado de Bienestar (1985/2005). Madrid: CIS.

Arias, X. C. y Costas, A. (2011). La torre de la ignorancia. Políticas y mercados después de la tormenta. Barcelona: Ariel.

OCDE (2011). Estamos divididos. Por qué la desigualdad sigue creciendo. [On line]. Disponible en http://www.oecd.org.

Krugman, P. (2009). El retorno de la economía de la depresión y la crisis actual. Madrid: Crítica. Judt, T. (2010). Algo va mal. Madrid: Taurus.

Inglehart, R. y Welzel, C. (2006). Modernización, cambio cultural y democracia: la secuencia del desarrollo humano. Madrid: CIS-Siglo XXI.

Laparra, M. y Pérez, B. (2011). El primer impacto de la crisis en la cohesión social en España. Madrid: Fomento de Estudios Sociales y de Sociología Aplicada (FOESSA).

Navarro, V. (2007). Informe 2007 del Observatorio Social de España. El Estado de Bienestar en España y las CC.AA. Análisis de indicadores clave. Madrid: Observatorio Social de EspañaMTAS.

Navarro, V., Torres, J. y Garzón, A. (2011). Hay alternativas. Propuestas para crear empleo y bienestar social en España. Madrid: Sequitur.

Noya, J. (2004). Ciudadanos ambivalentes. Actitudes ante la igualdad y el Estado de Bienestar. Madrid: CIS.

Rodríguez Cabrero, G. (2004). El Estado de Bienestar en España: debates, desarrollo y retos. Madrid: Fundamentos.

Sen, A. (2001). El nivel de vida. Madrid: Universidad Complutense.

Sevilla, J. V. (2011). El declive de la socialdemocracia. Barcelona: RBA.

Touraine, A. (2011). Después de la crisis. Por un futuro sin marginación. Barcelona: Paidós. 